\title{
Child Care
}

Child Care in Practice

\section{Risk Factors for Self-Harm: Narratives from a Sample of Young People in Northern Ireland}

\section{Elaine Pollock, Johanna O'Shea \& Campbell Killick}

To cite this article: Elaine Pollock, Johanna O'Shea \& Campbell Killick (2021) Risk Factors for Self-Harm: Narratives from a Sample of Young People in Northern Ireland, Child Care in Practice, 27:2, 139-154, DOI: $10.1080 / 13575279.2019 .1635083$

To link to this article: https://doi.org/10.1080/13575279.2019.1635083

\section{曲 Published online: 25 Jul 2019.}

Submit your article to this journal ¿

Џll Article views: 550

Q View related articles $₫$

View Crossmark data ¿ 


\title{
Risk Factors for Self-Harm: Narratives from a Sample of Young People in Northern Ireland
}

\author{
Elaine Pollock (iD) ${ }^{a}$, Johanna O'Shea (D) ${ }^{b}$ and Campbell Killick (D) \\ ${ }^{a}$ Children's Services, South Eastern Health and Social Care Trust, Downpatrick, Northern Ireland; ${ }^{\text {b Social Work }}$ \\ Department, Ulster University, Newtownabbey, Northern Ireland
}

\begin{abstract}
Self-harm continues to be a growing concern within adolescence and is a globally recognised public health and social problem. Adolescents living in the community who self-harm are extremely common however less is known about these young people. This study focussed on capturing the voice of young people who engage in cutting behaviour to provide insight into the risks associated with this phenomenon. Single semi-structured interviews were conducted with 9 adolescents aged 16-18 years who lived within one Trust area in Northern Ireland. Thematic analysis was applied to the transcribed interviews in which themes emerged. The three subordinate themes of onset, persistence and ending of the behaviour encompassed six subthemes which were further identified as risk factors for the behaviour. Risk factors identified were: ACE's, poor relationships and difficulties in support networks, exposure to self-harm, psychological issues, "addiction" to self-harm, concealment of harming behaviour-to control and professional and peer support that helps or hinders. These factors support the current literature base however individual and diverse explanations are highlighted which provide further depth, particularly around the concept of addiction and support that hinders young people. Despite the small nature of the study, recommendations for social work practice, clinical practice and other relevant professional practice as well as future research are considered in view of the findings. Key direction outlines the importance of building trusting relationships, continuity of care and continuing to listen to young people as vital to the helping relationship.
\end{abstract}

\section{KEYWORDS}

Self-harm; adolescence; risk factors; social work; young people; cutting; behaviour; voice of child

\section{Introduction}

The term "self-harm" was derived from the term "parasuicide" which was further defined and developed by the World Health Organisation (WHO)/Euro Multicentre Study Working Group as:

An act with non-fatal outcome in which an individual deliberately initiates a non-habitual behaviour, that without intervention from others will cause self-harm, or deliberately ingests a substance in excess of the prescribed or generally recognised therapeutic dosage,

CONTACT Elaine Pollock elaine.pollock@setrust.hscni.net $\mathrm{O}$ Children's Services, South Eastern Health and Social Care Trust, Downshire Estate, Ardglass Road, Downpatrick BT30 6RA, Northern Ireland 
and which is aimed at realising changes that the person desires via the actual or expected physical consequences. (DHSSPSNI, 2014, p. 8)

Hawton et al. (2003) suggest that this includes all intentional acts of self-poisoning (overdoses) or self-injury (skin-cutting) and can be recognised through varying global terms such as "self-injurious behaviour", "non-suicidal self-injury", "self-destructive behaviour" and "self-mutilation".

There appears to be controversy regarding whether self-harm is linked to suicidal intent, with some writers (Klonsky \& Muehlenkamp, 2007) advising that this behaviour is without the conscious intent of suicide, whereas Hawton et al. (2003) suggest that there is such intent. Irrespective of the degree of suicide intent, what is evident is that the act of self-harm causes "immediate destruction of body tissue" (Hagell, 2013; Kerr, Muehlenkamp, \& Turner, 2010) and there is, therefore, a correlation between self-harm and suicide (O'Connor \& Sheehy, 2000). This point is echoed in Northern Ireland through the development of the Northern Ireland Registry of Self-Harm which was piloted under the Northern Ireland Suicide Strategy "Protect Life-A Shared Vision". This registry operates across all five Trusts and provides valuable data regarding the extent of this health concern.

Recent information from the registry outlines that there were 25,620 presentations of self-harm (16,301 persons) to the 12 emergency departments in Northern Ireland across three years. In total 6271 persons presented due to cutting behaviour and 2642 persons who presented were under 18 years (70\% female), 780 of whom had selfharmed by cutting. Across the time period, the highest rates of presentations were made by 15-19-year-old females and 20-24-year-old males. The figures represent an increase in figures and outline that some individuals presented more than once (Public Health Agency, 2016).

Hagell (2013) identifies self-harm as a particular behaviour evident within adolescence and whilst young people under 18 years accounted for only $10 \%$ of all presentations (Public Health Agency, 2016), Hawton, Rodham, Evans, and Harriss (2009) outline that hospital-based figures represent only a fraction of the young people who self-harm as many do not attend hospital following an act of this behaviour. This view is supported by Hagell (2013) who advises that given this is generally a private behaviour, there is difficulty defining how prevalent it is. Despite this, across the U.K. and Ireland, selfharm in adolescence depicts one of the leading concerns in hospital admissions and is subsequently a public health and social problem (Hawton, Saunders, \& O'Connor, 2012) which in Northern Ireland appears to be escalating in frequency (Gillen, Kirby, McBride, McGlinchey, \& Rushe, 2019; O’Connor, Rasmussen, \& Hawton, 2014). It is also understood through research conducted by Bunting, Murphy, O’Neill, and Ferry (2012) that rates of mental disorder amongst adolescence in Northern Ireland are amongst the highest in Europe.

McAndrew and Warne (2014) outlined that literature relating to the perspectives of young people appears scarce in this topic area which interferes with social work principles of practice given the legislation that practitioners follow. Research on self-harm and risk factors that influence this behaviour has been conducted with psychiatric/patient populations (Klonsky \& Muehlenkamp, 2007; Laye-Gindhu \& Schonert-Reichl, 2005) and/or on adult samples (Tryer et al., 2003) leaving a caveat in the current evidence base. 
The current study focuses on capturing the voice of young people who engage in cutting behaviour to explore their views on the onset of self-harm behaviour, why young people engage in repeated incidents of self-harm and what helps them to stop or attempt to stop harming. This article will offer practitioners insightful information to support them in their direct work with young people.

\section{Methodology}

\section{Design}

The design selected for the study was a qualitative approach utilising Braun and Clarke's thematic analysis method (Braun \& Clarke, 2006). This approach was the most appropriate as it supported a focus on the meaning and sense young people make of their own experience of cutting behaviour.

\section{Sample}

Up to 16 young people (aged 16-18 years) who currently or had previously self-harmed by cutting were invited to participate in the study.

According to Morse (1994), studies which focus on gaining insight should include at least 6 participants, and offer saturation of data which is achieved between 5 and 50 interviews (Dworkin, 2012).

A criterion for inclusion was outlined for the study. Marshall (1996) identifies this as a purposeful sample; the most productive participants are selected who will be able to answer the question. Sandelowski (1995) adds that this provides opportunity to gain rich individual information. Eligibility to participate was defined by the young person being open to a social work service, not currently in crisis, able to consent to participate individually and not in receipt of treatment or involved in a criminal investigation. To reduce potential for bias, no young person who was known to the researcher through the social work service was included.

Young people were identified by their social worker based on a professional information sheet and risk assessment. Individuals identified were given a participant information sheet to enable an informed choice to engage. This was re-visited during the process of the study. Parental consent was not deemed necessary due to the age of the young people eligible for the study and private nature of the behaviour. A parental information sheet was made available to parents of young people who agreed to this support.

\section{Procedure}

Ethical approval for the study was provided by the Health and Social Care Trust, Ulster University and Health and Social Care Regional Ethics Committee in Northern Ireland. Good clinical practice training was also undertaken by the researchers.

A semi-structured interview pro-forma was agreed alongside a young person, a CAMHS (Child and Adolescent Mental Health Service) representative and a senior social worker as part of an advisory panel. Single, one-off interviews were conducted with the participants. 
Fourteen young people initially agreed to engage in the study however three young people went into crisis, one became mentally unwell and another changed their mind. Nine young people within one Trust area consented to engage in the study. Five young people were female; three were male and one young person did not identify with gender.

Data was generated between April 2018 and June 2018. Interview times were between 25 and $60 \mathrm{~min}$ and were dependent on the contribution the young person wished to make. All young people engaged voluntarily, there was no reward for doing so nor were there any implications for non-participation.

Interviews were conducted iteratively with alternative questions being amalgamated into the interview schedule when themes emerged or to clarify meaning. They were audio recorded to ensure an accurate record and subsequently transcribed verbatim. All young people were given the opportunity to read their transcribed information to ensure authenticity and credibility; only one young person engaged in this process.

\section{Data analysis}

A thematic analytical approach was applied to the data gathered. Analysis entailed revising transcriptions line by line to outline themes within the narratives. These were revisited to contextualise and develop categories. Once all nine transcripts were scrutinised in this way, categories were collapsed or expanded on when compared.

\section{Findings}

\section{Theme 1: risk for onset of self-harm (cutting) behaviour}

The age of onset of the cutting behaviour appeared to deviate within the cohort of young people engaging in the study. Age ranges were as low as 5 years old up to 16 years. Of particular concern, there were two young people who engaged in self-harm below the age of 10 years, whereas the majority of the group initiated this behaviour in their teenage years.

\section{Adverse childhood experiences (ACE's), poor relationships and difficulties in support networks}

A number of young people outlined the difficulties in their individual situation which contributed to them initiating self-harming behaviour. Issues within the immediate family network appeared particularly significant, with some young people not getting the support they required and moving to foster care or a care placement.

In four of the young people's accounts, the mental health of a parent appeared to have an influence on the young person themselves, namely in the parents' ability to effectively support their child and provide the basic care needs, "yeh her mental health was really bad and just basically the house was a complete mess" (YP, B), "like my mum was like an alcoholic and she was very mentally abusive" (YP, C). For one young person, mental health appeared to have been a feature with all family members, "my whole family, my sister tried to kill herself, my sister ... arms up and down, my mum arms up and down" (YP, D).

Two young people spoke directly about the significant and traumatic abuse they were exposed to for a lengthy period of time. One young person advised, "for a year and a half prior I was mentally, physically and sexually abused by my ma's boy" (YP, A). 
Domestic violence was also noted within the home environment in three young people's accounts whether they directly experienced this or witnessed it happening, "from about the age of three until about eight, I was involved in domestic violence as well so I was from my mum's ex-partner so I believe that may have triggered like the anger" (YP, F). Although one young person did not directly identify violence in the home, seeking support from Woman's Aid suggested this, "when I went to Woman's Aid with my mum, brother and sister and $\mathrm{mmm}$ it seems like I was there for ages but I was only there for two weeks then I went to foster care" (YP, B).

Two young people, in particular, spoke of the death of a parent which had naturally been traumatic for them at such a young age and left them feeling angry and disconnected from the family. Young person $\mathrm{G}$ advised,

my dad died when I was 10, and then, I started like hitting people ... I kept getting suspended and then I was getting kicked out of school after school so I just started cutting myself to get like all the anger out.

Young people were able to identify, given the family issues noted, that their family support networks were hampered. One participant spoke of taking on the role of the carer in his family "no I was the parent for a while ... they didn't care, so I took up, ... the parental role" (YP, A). The difficulties in the relationship with his parents and his parents' new partner was particularly striking and outlined the instability in his situation, "I didn't like her and she didn't like me most of the time so stayed with him for about 5 days and moved back in with her for like a day" (YP, A). Unfortunately, any degree of settlement for this young person only appeared to happen once he went into care.

For others, however, coming into the care of the Trust caused further issues and instability due to the environment being unnatural and them having to live with strangers. Another young person who went into foster care spoke of how she grew attached to the carer, but a change in the home dynamic caused this relationship to break down completely and her having to move placement.

Difficulties within relationships however extended beyond the family to peer associates in four young people's accounts with rejection, bullying and isolation being key features in school or the community. One young person spoke of how the rejection by a peer triggered difficult memories of the rejection he received from his family, "it just made me feel like really, really, really rejected and that like struck up old memories like why I was put into care and emm just like that's what started my mental health issues" (YP, D).

Bullying in school was notable in two young people's accounts due to appearance, this being the triggering factor for their self-harm behaviour,

in school I was being bullied so I was, I had people you know calling me fat every day, telling me to go slit my wrists, hang myself, and that just built up and built up until eventually I just broke but and at home I didn't want to take it out on my family so I took it out on myself which was then the self-harming. (YP, F)

\section{Exposure to self-harm}

Young people spoke of witnessing other people self-harm and this was how they came to be aware of it as a form of coping. Some outlined that they witnessed family members directly self-harming. Others spoke of the influence of peers in alerting them to the behaviour or a similar harming behaviour which appeared to manage emotions. 
Social media also played a part for one young person who identified television as a risk factor "I think my actual first exposure was actually Hollyoaks. Like you could visibly see it on the TV ... you saw her cut herself emm in a kitchen sink, and like multiple, multiple times it happened" (YP, D). For this particular young person, this verified the behaviour was inherent in society. Social media also outlined different forms of harm to this individual, "I didn't know about burning until I looked up like what could happen when you selfharm" (YP, D).

Three young people however advised that they had never been exposed to cutting behaviour prior to initiating it suggesting it being completely alien to them or a hasty reaction to a situation. One young person highlighted that he discovered cutting independently and this progressed, "I hadn't seen anyone self-harming, I picked up a flint stone and cut my finger, then I ended up cutting my leg" (YP, E).

\section{Psychological issues}

Cutting for some young people seemed to indicate a form of punishment for them particularly if they felt disappointed with themselves or wanted to blame themselves for a behaviour or event.

Having a negative self-image also came across in three young people's narratives with one young person outlining how little they thought of themselves, "I don't love myself, I hate me, I am a loser, I am a ${ }^{* *} k$ up" (YP, F), another feeling they deserved to be scarred, and the final young person engraving their negative viewpoint on their body, "I'm carving the word fat into my stomach because I believe that I am fat and for being this big, I should feel pain for it" (YP, D). The idea of cutting in order to feel pain appeared particularly significant for young people who struggled with the negative feelings associated with their situation. In a number of accounts, pain signified that the cutting behaviour brought the person back to reality with one young person advising that pain acted as a barrier, blocking reality out.

Releasing emotions was also a function of the self-harm behaviour. One young person explained that he kept taking his anger out on other people but by releasing it through cutting this stopped,

I was taking all my anger out on people but like, I kept getting suspended and then I was on my last warning with my third school in the space of three years, so like, I had to stop so I started cutting myself. (YP, G)

$\mathrm{He}$, therefore, transferred the harm from others to himself.

There was debate within the accounts as to whether self-harm was linked to suicidal intent with some young people stating that this was their rationale every time they cut and others stating they felt suicidal on some occasions. "It wasn't really just to get over the situation; it was to end the situation", YP, H said when discussing cutting. Whilst one young person stated that he felt so low he wanted to commit suicide, he never wished to do this through self-harm; rather this appeared to support him throughout difficult stages in his life, "it was really bad coping mechanism, but I wanted it to be that. I wanted it to be my release" (YP, D).

Communication difficulty came across within the narratives. Some young people felt unable to speak about their feelings and emotions due to personal difficulties, "people say you need to talk about it, but what's the point of talking about it if you can just 
about get through it in your head" (YP, I), or concern over others reactions. Another young person advised that they did not want others to be concerned.

The lack of open communication, however, prevented the young people in gaining support with psychological issues, "they couldn't do anything because I never spoke" (YP, A), with one individual seeing this as a form of weakness, "support means you can't get through it yourself, ... so it's either do it yourself or don't do it at all” (YP, D).

\section{Theme 2: risk associated with persistence of cutting}

\section{Addiction to self-harm}

The majority of young people who took part in the study spoke of how they continued to cut because it became an "addiction" for them or in some way normal due to their length of engagement in the behaviour. There was however differentiation as to what the "addiction" meant to them as individuals. The word "addiction" was used specifically in five young peoples' accounts without prompting or influence. "Addiction" was interpreted as the young people engaging in the behaviour repeatedly despite potential detrimental consequence. This was simply described by one young person,

I feel like it's an addiction like, self-harm, it's so stupid though it's just like, you get sad then you cut yourself and then I regret it, and then I get sad so I cut myself and it's just like ongoing cycle. (YP, B)

The cutting aspect of the behaviour was not the "addiction" the young people described, in fact, one participant spoke of there being different hierarchies of risk, with the severity dependent on what aspect of the behaviour the individual was "addicted" to. This young person spoke of how they were addicted to seeing blood however described clearly the hierarchy of the overall areas of "addiction", "I liked looking at the blood and that was the addiction of it, but like some people's addictions are more severe, some people do get addicted to the scars maybe or even worse, the pain, and they'll cut deep" (YP, D).

Further aspects of the behaviour were outlined by one young person who advised that people can be "addicted" to self-harm behaviour as it provides a pleasurable effect. In his account, he was not referring to himself, but was aware that this was a factor in relation to "addiction", "people do it for the endorphins which eventually becomes an addiction to the endorphins" (YP, A).

Despite the rationale behind the "addiction" to cutting behaviour, two participants spoke about difficulty in stopping the behaviour and how over time they realised that it had not been helpful to them in their situation.

\section{Concealment of harming behaviour-to control}

Young people spoke of self-harm as a behaviour they could conceal from others and some portrayed their ability to do so in an almost boastful manner; as a level of independence and choice in their life which influenced a continuation of the behaviour. One young person spoke of how they felt that this was something in their life they had authority over,

like I always felt that self-harming was like a control thing because like I've been in care since I was 8, like I've never had any control over my life, it was always like social workers or other people ... I think that's why I stuck with it for so long even though I didn't control it because it kinda controlled me. (YP, B) 
In this sense, most young people stated they cut in places on their body that could be hidden from others. Conversely, however, one individual did not wish to hide their injuries as they felt used to people staring at them, “once you stop caring you don't, like you'll do anything. Like I would emm would walk out, short sleeved shirts, fresh cuts, didn't care" (YP, D).

Hiding the cutting behaviour appeared to add to the intensity of the behaviour for some with one person placing a lot of emphasis on the reason behind the need to cut and the justification for injuring themselves. The number of cuts appeared to differ depending on the rationale behind the cutting behaviour. For one adolescent, it depended on whether there was space on their arm to cut,

I only cut on the outside of my arm, so, if there was a gap, I would never cut on the inside because of the veins, I just can't stand veins, ... and if there was a gap, there was a gap. $(\mathrm{YP}, \mathrm{H})$

Not requiring medical treatment appeared to support the hidden behaviour, some recognised however that they should have received medical treatment, but chose not to, so they could continue to mask their cutting particularly from professionals who may document the behaviour.

At times, however, the young people did not always have control over the behaviour and therefore were not always able to hide it. This appeared to be when they cut too deep or in dangerous areas and intervention was necessary from others, like this young person who stated (when discussing a self-harm incident), "I did about 75 and about half of them were on the veins, like proper veins so I scared the $s^{\star *} t$ out of the staff cause even the doctor turned round to me and goes I should have died" (YP, A).

\section{Influence of self-harm within society}

The majority of young people who took part in the study spoke about a commonality in the behaviour and normalisation particularly within peer groups, which to some degree justified their continuation in the behaviour. Some of the young people lived or had lived in Trust residential facilities alongside other young people, "I was 15 and in a care home, all the girls were doing it, I seen it and it looked a bit easier and I could do it more often cause I wasn't the only one" (YP, E). Other young people outlined the severity of the behaviour in the community with some detailing the behaviour to be well established.

\section{Untreated mental health issues}

Four of the adolescents spoke of specific mental health issues such as anxiety and depression which appeared to influence their cutting behaviour over time. Depression was expressed by one young person in a poem they read from their diary. This was interpreted as that young person feeling so low and vacant at times that cutting or pain was the only thing they could feel,

I am depression. I am the emptiness you feel at $2 \mathrm{am}$. The tears with no meaning. The pain when you smile. I don't come alone. I bring my closest friends, we are the scars that cover your body, the voice you despise but soon to learn trust, I am the only thing you will feel. $(\mathrm{YP}, \mathrm{F})$ 
Young people, however, highlighted that having mental health issues does not dictate that people will self-harm for that reason, but that they may do this to draw attention to their mental health issue. It was also suggested by some that other factors may impact on individuals mental health, which could add to their need to self-harm, such as sleep deprivation and substance misuse, with substance misuse at times replacing the urge to cut, "that's how everyone dealt with their pain, or else we got drunk or took drugs to try to forget things" (YP, E).

Regardless of having a diagnosis or a label, a number of young people spoke of emotions that built up again over time resulting in repeated episodes of harm. One individual spoke of how they understood that they would need to cut again, "until next time" (YP, I).

In some instances, the repetition of cutting was due to difficult situations the young person was experiencing, or in relation to remembering difficult memories at different points in time,

it depends what month it is or like what time of the year it is cause I have, I always remember dates of like bad events and stuff like that and usually around then, like things get really bad for me. (YP, B)

One young person summarised their difficult feelings similar to "a coca cola bottle, you know the way you shake it and it just explodes" (YP, H), when justifying the recurring behaviour.

\section{Theme 3: ending the behaviour}

\section{Professional and peer support that helps or hinders}

A number of participants described their motivation in trying to stop cutting themselves. For some, this appeared to be due to a change in their situation, "I love my girlfriend and she is my priority now" (YP, E) or hobby, "that Christmas I got a weights bench so, now, every time I got angry or every time I got home and had nothing to do, I just did weights" (YP, A) or a change in their thought process. Other young people stopped for appearance reasons, "I want to be able to wear like nice stuff in the summer, like I'm sick of always having to wear long sleeves" (YP, I).

Two young people spoke of alternative ways of coping with their feelings, and using different approaches to manage their emotions, for instance for one young person, drawing on her legs and writing in a diary; although this was not always effective,

sometimes, it did, it helped, other times when you were writing it down and because you were writing it down you started thinking and it brought it back up and then it got the emotions back up again so there's pros and cons to it. (YP, F)

Writing for another young person did prove beneficial.

The ability to self-help appeared to be an important trait in supporting young people to reduce or stop cutting and limit their chance of relapse. One young person found that when he was able to stop his medication and enrol in college independently, incidents were less frequent. Another young person highlighted a self-awareness regarding their mood, was able to seek support at the correct time and this prevented relapse.

That said, not all young people are able to help themselves in this way and did not recognise that others can help, "if it was at the point where I was like self-harming I 
really felt like alone, I didn't feel like there was anyone who could help" (YP, B). There was also suggestion that some young people are not able to communicate with others to gain the support; or their thoughts and feelings are too difficult to communicate at that time.

The closest support network to any young person should be their family however two young people spoke of unhelpful responses from family members that limited their ability to continue to gain this support. Family members responded in both situations negatively stating that the young person was seeking attention.

Seven of the young people spoke of helpful support from their peers. For some this was due to having a good relationship; "we were talking and then you know you would get that good bond with people then you would open up" (YP, F), for others because their friend gave them time to talk or did not judge them.

Interestingly support from peers tended to be particularly helpful due to a shared level of understanding and commonalities in situations. One young person felt very strongly about shared experience stating, "I would just find it really tedious to sit with an adult who has never self-harmed, who has never experienced actual diagnosable depression" (YP. D), conversely, another person felt their situation improved when they changed their peer group from those who were engaging in similar behaviours.

Not all young people felt as enthusiastic about professional support for various reasons with professionals receiving much more criticism. Three young people, in particular, spoke of how their involvement with CAMHS (mental health service) had not been helpful as the practitioner had tried to ask about difficult traumatic memories. By doing this, and without trust being built, the young people lost faith in the support service and refused further engagement, "no I didn't like her because every time she tried to come see me, she used to try and hit the things that hurt the most, so I didn't find that useful" (YP, H).

Engagement with CAMHS also concluded for one young person following a change in the practitioner,

I had one of the really dead on people so I started talking to them and then one day they gave me someone different ... he didn't understand anything and tried to go straight into the deep end and I was like mate, shut the $\mathrm{f}^{\star *} \mathrm{k}$ up (YP, A),

and for another due to an inability in building a relationship.

Young people were frustrated by professionals that they felt were unhelpful, insincere or uncaring,

when I was getting like seen by professionals, I just felt like oh I'm just like another person out of like 100's of other people that they have. It wasn't like, I didn't feel like they really cared about me, I just felt like, oh it's another job to do, it's just like something else to do, type thing. $(\mathrm{YP}, \mathrm{C})$

Refusal to engage in professional support was in some way linked to young people wanting to keep their private life private. One participant outlined how having professional involvement and their privacy invaded, was extremely overwhelming for them

I'm a very private person, especially then cause I was never like involved with anyone like social services or anything like that so like the fact that everyone was ... like talking to me all at once, it was very overwhelming. (YP, C)

Young people recognised that their level of motivation was a key factor in gaining support but waiting times, length of involvement and the formality of the setting were 
also seen as having an impact on their engagement. Despite this, some participants recognised the benefits of professional support even at times when it was not their choice to have professionals in their lives, "when I was put into hospital when I was 16 that's only when I started getting treatment for like, like stitches and stuff" (YP, C), "I think talking to people was helpful, like ${ }^{* * * * *}$ had me, my social worker, he was a good help, know what I mean" (YP, G).

Although there was little consensus as to what the best support was, all of the young people provided insight into why their individual support was helpful to them or what valuable support would look like. One young person placed emphasis on the relationship, "I think that to be able to talk to someone, you really have to click with them" (YP, B) with others outlining the importance of being available and having good listening skills, "always listen to what they are doing it for and why they are doing it and just give them as much help as you can because it does work, listening helps" (YP, G),

\section{Discussion and recommendations}

Existing literature formed the basis of this study providing a structure for interview questions. Expert validation, however, was utilised when creating the interview schedule to offer an independent perspective and reduce bias.

\section{Theme 1: risk for onset of self-harm (cutting) behaviour}

Research is clear as to how traumatic events can have negative, lasting effects on health and well-being with authors like Devaney, Bunting, Hayes, Lazenbatt, and Spratt (2012) explaining that the more adverse childhood experiences (ACE's) a young person is exposed to, the more likely they are to experience poor outcomes in adolescence or beyond. Dube et al. (2003) offer further insight, stating that there is a significant correlation between ACE's and attempted suicide throughout the lifespan of an individual. It is of great concern that all of the young people in this study experienced some form of adversity whether through abuse, neglect or other household challenges such as the death of a parent, substance misuse or domestic violence. Screening for these adversities is evident in social work practice however consideration should be given to the specific behaviours that could arise from adverse experiences and support given as necessary.

Difficulties within relationships came to the fore with young people recognising volatility in their family support networks, peer relationships and within school. Feelings of rejection, bullying and isolation appeared to trigger difficult emotions which led to selfharm. Considering this is a difficult developmental stage whereby the young person wants to belong to society and fit in (Erikson, 1963), it is not surprising that it is a stage which risks the development of psychological issues and distress if the young person does not feel a sense of belonging or cohesion in supports.

There was limited clarity in previous studies on whether exposure to self-harm through family, peers or social media was a standalone risk factor for this behaviour (Hasking, Andrews, \& Martin, 2013) with Spears, Montgomery, Gunnell, and Araya (2014) highlighting that precursors are associated with other factors such as adversities. This study supports this notion particularly if the behaviour is seen as a coping mechanism in 
respect of adverse experiences. Young people can take on negative coping mechanisms developed by their parents or care givers which not only identifies exposure as a risk but also more complex issues within the home (Gromatsky et al., 2017). Risks of persistence of the behaviour also appear to increase through exposure to the behaviour, with young people identifying with the established and common nature of this in society.

Low self-esteem, unworthiness and self-criticism all came across in the young people's accounts with cutting forming a response of punishment. This idea is widely reported in current literature (Muehlenkamp \& Brausch, 2012; Xavier, Pinto-Gouveia, \& Cunha, 2016), however young people also reported cutting as a function of releasing emotions and to bring them back to reality, therefore they cut in order to help deal with difficult emotions (Kidger et al., 2015). In practice it is important to understand that these feelings may have origins in early childhood and have developed and strengthened over time. Consistent with previous research, the participants recognised their difficulty communicating and for differing reasons internalising issues (Xavier et al., 2016). This however limited opportunity for support.

\section{Theme 2: risks associated with persistence of cutting}

Some young people described their cutting behaviour as an "addiction" as they came to depend on the emotional release, the feeling of pleasure and the sight of blood. Some research does identify with this description of the behaviour (Favazza \& Conterio, 1989; Spandler, 1996; Sutton, 2007). Sutton (2007) outlines self-harm as a cycle, understanding that cutting releases negative emotions and this can be pleasurable. Little attention, however, has been given to "addiction" to seeing blood. Recent research suggests that young people do engage in repeated episodes of the behaviour, and it is not a one-off event (Spears et al., 2014; Xavier et al., 2016).

Addiction services in Northern Ireland appear limited to substance misuse, sexual behaviour, smoking and gambling with some exclusive to the adult population. There may be benefit in considering self-harm in this continuum as to whether it can be categorised as an addiction particularly if professionals and support services are to try to support young people effectively.

Having perceived control over the behaviour was indicated by some participants as a risk for persistence. Young people explained this as the only form of choice they had despite recognising the "addictive" nature of the behaviour having control over them. Due to this, they hid the behaviour from others or engaged at a level that did not bring them to the attention of others including medical professionals (Hawton et al., 2009) leading to further vulnerabilities especially if the behaviour progressed.

Experiencing difficult situations which cause distress or remembering the past appeared to influence the emergence of difficult emotions which build up over time and lead to selfharm. Continued incidence of the behaviour in this regard support notions of the repetitive nature of the behaviour as a form of coping and can be considered within the "addictive cycle" noted previously (Xavier et al., 2016).

The study outlined however that other factors outside of adversities were known to impact on the young person's mental health such as sleep deprivation and substance misuse. This is well supported in the literature base (Hysing, Sivertsen, Stormark, \& O'Connor, 2015; O'Connor et al., 2014). Consistent with research carried out by 
Hasking et al. (2013) one young person identified that substance misuse can also act to suppress an individual's urge to self-harm and adopted to help cope with the same underlying urges of the self-harm behaviour.

\section{Theme 3: ending the behaviour}

Research by Caldwell (2014) outlined that adolescents need consistent and trusting relationships to disclose any maltreatment. It makes sense then that young people may find it difficult to communicate private realities without a strong cohesion whether with family, friends or professionals.

With regards to family, unhelpful responses such as, "they were doing it for attention" appeared to support a continuation of this behaviour. This in some ways links to the rejection/isolation the young person has felt from family. Adolescents want to feel accepted for who they are and want support from family or a safe base to further explore society (Erikson, 1963), without this they may continue to have negative feelings.

A number of participants outlined that their best source of support came from peers with shared commonalities of self-harm. However, there are known difficulties with this particularly as exposure to the behaviour can support the persistence of it (Hasking et al., 2013). This also creates complications within the professional relationship given professional boundaries of sharing personal information during direct work. Whilst the majority of the young people within the study continued to cut at stressful times, it must be noted that given the repetitive nature of the behaviour, it is likely that support needs to be lengthier. Friends in this regard are important.

Professional responses at times were not helpful and this appeared due to the relationship and whether trust was built. Young people described being asked deep and intrusive questions, feeling like a number in a service and having their privacy invaded. It is understandable from a professional perspective to look at the underlying triggers of behaviour to help address it. However, despite pressure on our support systems, practitioners need to recognise that timing is important when directly working with adolescents and caution needs to be taken in this approach.

\section{Limitations}

This research is based on nine interviews with adolescents identified as appropriate by their support staff. Young people excluded from the study may have had different experiences or perceptions. A longer time frame for the study would likely have yielded a larger sample size which would have further strengthened the findings. However, important perspectives have been gathered from this hard-to-reach group and saturation of information was achieved.

\section{Conclusion}

This study aimed to strengthen the current evidence base regarding the risks of onset, persistence and ending of self-harm (cutting) behaviour to provide professionals with insightful information from young people to aid their direct work with this vulnerable group. Despite the small nature of this study, the valuable contributions made by the young 
people should be considered as important feedback in guiding social workers, clinical professionals working in CAMHS and other relevant professional practice.

The study identified six key risk factors that span across onset, persistence and ending of the behaviour, the majority of which are well supported within the literature base. The risk factors identified include ACE's, poor relationships and difficulties in support networks (particularly where the young person has experienced adversities, been bullied, feels rejected or isolated), exposure to self-harm (through friends or family and where there are underlying issues), psychological issues (where the young person has low selfesteem, feels unworthy, is self-critical, has difficulty communicating and internalises issues), addiction to self-harm (to release emotion, for pleasure or to see blood), concealment of harming behaviour-to control (particularly when the young people feels little control) and professional and peer support that helps or hinders (where there is no trust, and the helping relationship is not built).

For professionals in practice this means that:

- Assessments need to identify key risk factors (adverse childhood experiences) as early as possible as early intervention may prove beneficial in gaining the correct support to help prevent the risk of self-harm in adolescents.

- Practitioners need to be creative in their approach with adolescents and adopt a responsive approach which is timely to the pace of the individual.

- Services of support such as CAMHS, should be more flexible and cognisant of the reality that individuals may become ambivalent about receiving services at different stages of their lives.

- Consideration needs to be given to the addictive nature of the behaviour. Despite this, support services should recognise the repetitive nature of self-harm and adapt their provisions to meet this need. Consideration may include peer support groups or mentors, particularly those with direct experience of the behaviour.

- The quality of relationships and having a sense of belonging is important to young people, therefore, relationship building continues to be integral to effective social work and clinical practice. Practitioners across disciplines need to spend time listening to what those who self-harm say and gain the trust of the young person.

- Caution should be taken when exploring trauma prior to a trusting relationship being built; continuity of care therefore becomes vital to the helping relationship. Failure to heed this recommendation could result in further trauma, relationship breakdown and limit on-going support for the young person.

Future research may look at capturing the narratives of a wider and more diverse sample group which could enable generalisation to adolescents who engage in this behaviour. Since this study focussed specifically on cutting behaviour, further research may explore other forms of self-harm including burning or scratching to identify whether the functions correlate.

\section{Acknowledgements}

We would like to thank wholeheartedly the young people who took part in this study for the significant independent contributions they have made and for allowing us to explore their individual 
experiences of self-harm behaviour. The study could not have been completed without the advocacy and agreement from the Trust who supported the study being conducted.

\section{Disclosure statement}

No potential conflict of interest was reported by the authors.

\section{Notes on contributors}

Elaine Pollock is a Senior Social Worker in a Child and Family Team in Children's Services for the South Eastern Health and Social Care Trust. She completed this study as part of an M.Sc. Professional Development in Social Work through the Research and Evaluation Methods Course within Ulster University. She has a keen interest in self-harm and relationship building in Social Work.

Johanna O'Shea is a Lecturer in Social Work within Ulster University in Northern Ireland. She is the course director for the Research and Evaluation Methods postgraduate course.

Dr. Campbell Killick is a lecturer in Social Work within Ulster University in Northern Ireland. He has recently moved from the post of Research Officer within the Training and Development Team in the South Eastern Health and Social Care Trust.

\section{ORCID}

Elaine Pollock (D) http://orcid.org/0000-0001-6099-8755

Johanna O'Shea (D) http://orcid.org/0000-0003-3278-2660

Campbell Killick (D) http://orcid.org/0000-0002-8421-2005

\section{References}

Braun, V., \& Clarke, V. (2006). Using thematic analysis in psychology. Qualitative Research in Psychology, 3(2), 77-101.

Bunting, B. P., Murphy, S. D., O’Neill, S. M., \& Ferry, F. R. (2012). Lifetime prevalence of mental health disorders and delay in treatment following initial onset: Evidence from the Northern Ireland study of health and stress. Psychological Medicine, 42, 1727-1739.

Caldwell, J. (2014). The prevalence of domestic violence among safeguarding cases involving adolescents in South Eastern Health \& Social Care Trust. University of Ulster and Partners.

Department of Health Social Services and Public Safety. (2014). Northern Ireland registry of selfharm 2013/14. Belfast: Department of Health Social Services and Public Safety (DHSSPS).

Devaney, J., Bunting, L., Hayes, D., Lazenbatt, A., \& Spratt, T. (2012). The impact of early childhood experiences on adolescent suicide and accidental death. Belfast, Department of Health, Social Services and Public Safety. BMC Medical Research Methodology, 14, 42.

Dube, S. R. D., Anda, R. F., Felitti, V. J., Chapman, D. P., Williamson, D. F., \& Giles, W. H. (2003). Childhood abuse, household dysfunction and the risk of attempted suicide throughout the life span. Findings from the adverse childhood experiences study. Paediatrics, 111(3), 564-572.

Dworkin, S. L. (2012). Sample size policy for qualitative studies using in-depth interviews. Archive of Sexual Behaviour, 41(6), 1319-1320.

Erikson, E. H. (1963). Youth: Change and challenge. New York: Basic Books.

Favazza, A. R., \& Conterio, K. (1989). Female habitual self-mutilators. Acta Psychiatrica Scandinavica, 79, 283-289.

Gillen, A. M. C., Kirby, K., McBride, O., McGlinchey, E., \& Rushe, T. (2019). Comparing self-harm $(\mathrm{SH})$ thoughts and behaviours among a community sample of younger and older adolescents in Northern Ireland. Child Care In Practice, 25(2), 189-199. 
Gromatsky, M. A., Waszczuk, M. A., Perlman, G., Salis, K. L., Klein, D. N., \& Kotov, R. (2017). The role of parental psychopathology and personality in adolescent non-suicidal self-injury. Journal of Psychiatric Research, 85, 15-23.

Hagell, A. (2013). Adolescent self-harm (Research summary no. 13). Association for Young People's Health.

Hasking, P., Andrews, T., \& Martin, G. (2013). The role of exposure to self-injury among peers in predicting later self-injury. Journal of Youth and Adolescence, 42(10), 1543-1556.

Hawton, K., Harriss, L., Hall, S., Simkin, S., Bale, E., \& Bond, A. (2003). Deliberate self-harm in Oxford, 1990-2000: A time change in patient characteristics. Psychological Medicine, 33, 987996.

Hawton, K., Rodham, K., Evans, E., \& Harriss, L. (2009). Adolescents who self-harm: A comparison of those who go to hospital and those who do not. Child Adolescent Mental Health, 14, 24-30.

Hawton, K., Saunders, K. E. A., \& O’Connor, R. (2012). Self-harm and suicide in adolescents. Lancet, 379, 2373-2382.

Hysing, M., Sivertsen, B., Stormark, K. M., \& O'Connor, R. C. (2015). Sleep problems and self-harm in adolescence. The British Journal of Psychiatry, 2017(4), 306-312.

Kerr, P. L., Muehlenkamp, J. J., \& Turner, J. M. (2010). Nonsuicidal self-injury: A review of current research for family medicine and primary care physicians. Journal of American Board of Family Medicine, 23(2), 240-259.

Kidger, J., Heron, J., Leon, D. A., Tilling, K., Lewis, G., \& Gunnell, D. (2015). Self-reported school experience as a predictor of self-harm during adolescence: A prospective cohort study in the South West of England (ALSPAC). Journal of Affective Disorders, 173, 163-169.

Klonsky, D. E., \& Muehlenkamp, J. J. (2007). Self-injury: A research review for the practitioner. Journal of Clinical Psychology, 63(11), 1045-1056.

Laye-Gindhu, A., \& Schonert-Reichl, K. A. (2005). Nonsuicidal self-harm among community adolescents: Understanding the "whats" and "whys" of self-harm. Journal of Youth and Adolescents, 34(5), 447-457.

Marshall, M. N. (1996). Sampling for qualitative research. Family Practice, 13(6), 522-525.

McAndrew, S., \& Warne, T. (2014). Hearing the voices of young people who self-harm: Implications for service providers. International Journal of Mental Health Nursing, 23, 570-579.

Morse, J. M. (1994). Designing funded qualitative research. In N. K. Denzin \& Y. S. Lincoln (Eds.), Handbook of qualitative research (pp. 220-235). Thousand Oaks, CA: Sage.

Muehlenkamp, J. J., \& Brausch, A. (2012). Body image as a mediator of non-suicidal self-injury in adolescents. Journal of Adolescents, 35, 1-9.

O'Connor, R. C., Rasmussen, S., \& Hawton, K. (2014). Adolescent self-harm: A school-based study in Northern Ireland. Journal of Affective Disorders, 159, 46-52.

O'Connor, R., \& Sheehy, N. (2000). Understanding suicidal behaviour. London: BPS Blackwell.

Public Health Agency, Northern Ireland. (2016). Registry of self-harm three-year report 2012/2013 to 2014/2015. Belfast: Department of Health.

Sandelowski, M. (1995). Focus on qualitative methods: Sample size in qualitative research. Research in Nursing and Health, 18, 179-183.

Spandler, H. (1996). Who's hurting who? Young people, self-harm and suicide. 42nd street - community based mental health resource for young people.

Spears, M., Montgomery, A. A., Gunnell, D., \& Araya, R. (2014). Factors associated with the development of self-harm among a socio-economically derived cohort of adolescents in Santiago, Chile. Social Psychiatry and Psychiatric Epidemiology, 49(4), 629-637.

Sutton, J. (2007). Healing the hurt within: Understanding self-injury and self-harm, and heal the emotional wounds (3rd ed.). Oxford: How to Books.

Tryer, P., Thompson, S., Schmidt, U., Jones, V., Knapp, M., \& Davidson, K. (2003). Randomized control trial of brief cognitive therapy versus treatment as usual in recurrent deliberate selfharm: The POMPACT study. Psychological Medicine, 33, 969-976.

Xavier, A., Pinto-Gouveia, J., \& Cunha, M. (2016). Non-suicidal self-injury in adolescence: The role of shame. Self-Criticism and Fear of Self-Compassion. Child and Youth Care Forum, 45(4), 571586. 